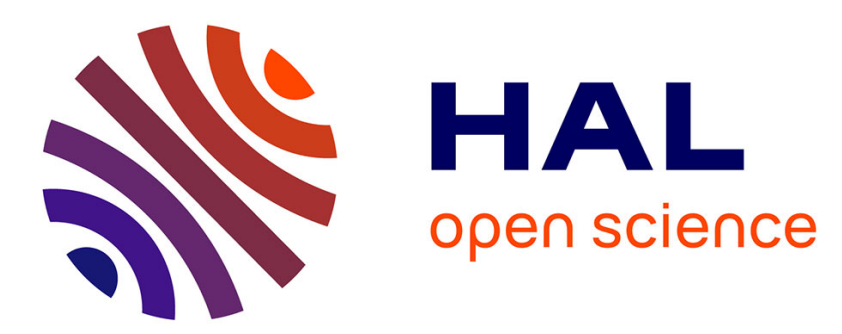

\title{
Experimental analysis of drying shrinkage cracking in coating mortars by digital image correlation
}

F. Benboudjema, T Mauroux, Ph Turcry, A Ait-Mokthar, O. Deves

\section{To cite this version:}

F. Benboudjema, T Mauroux, Ph Turcry, A Ait-Mokthar, O. Deves. Experimental analysis of drying shrinkage cracking in coating mortars by digital image correlation. Concreep 2013, Sep 2013, Boston, United States. hal-01695982

\section{HAL Id: hal-01695982 \\ https://hal.science/hal-01695982}

Submitted on 29 Jan 2018

HAL is a multi-disciplinary open access archive for the deposit and dissemination of scientific research documents, whether they are published or not. The documents may come from teaching and research institutions in France or abroad, or from public or private research centers.
L'archive ouverte pluridisciplinaire HAL, est destinée au dépôt et à la diffusion de documents scientifiques de niveau recherche, publiés ou non, émanant des établissements d'enseignement et de recherche français ou étrangers, des laboratoires publics ou privés. 


\title{
Experimental analysis of drying shrinkage cracking in coating mortars by digital image correlation
}

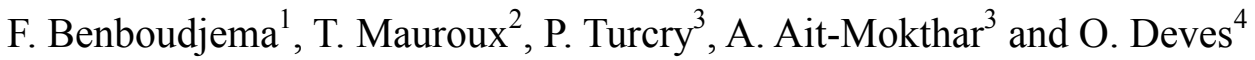 \\ ${ }^{1}$ LMT-Cachan, ENS-Cachan, Paris 6 University, CNRS, UniverSud Paris PRES, \\ France; email: farid.benboudjema@ens-cachan.fr \\ ${ }^{2}$ SITES, 2 bis Avenue du Centre 92500 Rueil Malmaison, France \\ ${ }^{3}$ University of La Rochelle, LaSIE - CNRS FRE 3474, France \\ ${ }^{4}$ CSTB Marne-la-Vallée, France
}

\begin{abstract}
Since drying is a very slow process, a strong gradient of drying shrinkage occurs in concrete members leading, at the macroscopic level, to the rise of tensile stresses at the surface and compressive stresses at the core. Therefore, it may lead to superficial cracking. In addition, crossing cracks and/or debonding (at the interface with a substrate) may also occur in thin members if drying shrinkage is restrained. In order to study these phenomena, a new device based on digital image correlation (DIC) was set-up. A post-processing tool is then proposed to capture the mapping of shrinkage strains and to determine the evolution of the cracking patterns. It was used successfully to observe, quantify and analyze cracking of a coating mortar, due to the restraint of drying shrinkage by a rigid substrate (concrete block).
\end{abstract}

\section{INTRODUCTION}

Since drying is a very slow process, a strong gradient of drying shrinkage occurs in concrete members leading, at the macroscopic level, to the rise of tensile stresses at the surface and compressive stresses at the core. Therefore, it may lead to superficial cracking. In addition, crossing cracks and/or debonding (at the interface with a substrate) may also occur in thin members if drying shrinkage is restraint (like in reparation, coating mortar, slabs, tile mortar, by a concrete lift ...). The consequences are the reduction of the durability of the construction, since the apparent permeability and diffusivity are increased. In cladding unit (using rendering mortar), the efficiency of the insulating material may be reduced if it comes in contact in water (in the case of external thermal insulation), the loss of adhesion of the rendering mortar may occur and associated esthetical considerations may force the constructor to remove and lay again the rendering mortar.

In order to study these phenomena, a new device based on digital image correlation (DIC, developed by Besnard et al., 2006) was set-up. The DIC method is based on the comparison of two images (shot with a CANON EOS 450D camera) with two 
random gray levels recorded before and after a displacement. Compared to intrusive devices (SEM, embedded gauges ...), parasite cracks are not induced. Moreover, representative geometries and restraint conditions of rendering mortars can be used. Finally, it is here possible to obtain field of displacements and not only local information.

A post-processing tool is then proposed to capture the mapping of shrinkage strains (computed after interpolation of the displacement using quadrangular functions) and to determine the evolution of the cracking patterns. Besides, this enables also to quantify cracks openings, depths inside the mortar and debonding.

The device was validated by comparison with measurements of drying shrinkage using LVDT and investigations with an optical microscope. It was used successfully to observe, quantify and analyze cracking of cement-based materials (coating mortar, $\mathrm{w} / \mathrm{c}=1$, containing cellulose ether) due to the restraint of drying shrinkage by a rigid substrate (concrete block of controlled roughness). The mortar was dried at the age of 1 day, as the concrete substrate is at least 1 month old. Micro-cracks were detected going from the drying surface to the interface. The shrinkage of the mortar layer induces shear stress at the mortar/concrete interface, which results in debonding. Each one of these cracks was confirmed by optical microscopy observations.

\section{EXPERIMENTAL PROGRAM}

\section{Mortar mix, geometry and conditions.}

The mix of the studied mortar is given in the Table 1. The high value of the water to cement ratio $(\mathrm{w} / \mathrm{c}=1)$ has been fixed by the industrial consortium CEReM who supported this research program. The mortar contains a hydroxyl-methyl-propyl cellulose (HMPC) addition, which has water retention properties and is classically used in mortar used in cladding unit.

Table 1. Mortar mix.

\begin{tabular}{lllll}
\hline Siliceous Sand & $\begin{array}{l}\text { Portland } \\
\text { cement } \\
\text { (CEM I 52.5) }\end{array}$ & $\begin{array}{l}\text { Siliceous Filler } \\
\text { (Sifraco) }\end{array}$ & $\begin{array}{l}\text { Cellulosic } \\
\text { ether (MHPC) }\end{array}$ & w/c \\
\hline $650 \mathrm{~kg} / \mathrm{m}^{3}$ & $300 \mathrm{~kg} / \mathrm{m}^{3}$ & $50 \mathrm{~kg} / \mathrm{m}^{3}$ & $0.11 \%{ }^{*}$ & 1 \\
\hline$\%$ by weight of the cement content & &
\end{tabular}

Tested mortar specimens were protected from drying by a cellophane film and kept at $25 \pm 2{ }^{\circ} \mathrm{C}$ for 24 hours after mixing. After demoulding, they were placed in a room at $25^{\circ} \mathrm{C}$ and $30 \pm 5 \%$ of relative humidity $(\mathrm{RH})$.

Three types of elements have been casted (note that a thickness of $1 \mathrm{~cm}$ is used classically for the rendering mortar in industrial applications):

- $2 \times 4 \times 16 \mathrm{~cm}$ prismatic specimens (free drying shrinkage): the two opposite lateral faces $(2 \times 16 \mathrm{~cm})$ and the two end faces $(2 \times 4 \mathrm{~cm})$ were insulated by adhesive aluminum foils in order to prevent drying by these faces. These hydric boundary conditions were adopted in order to have a symmetrical 
drying problem and to avoid curling. Drying shrinkage strains are measured using LVDT;

- $1 \times 20 \times 20 \mathrm{~cm}$ prismatic specimens (free drying shrinkage): the drying is allowed only by the 2 faces of 20 by $20 \mathrm{~cm}$. Drying shrinkage is measured by DIC;

- $2 \times 20 \times 20 \mathrm{~cm}$ prismatic specimens (restrained drying shrinkage): the drying shrinkage is restraint by standardized concrete blocks with cubic dimensions $\left(20 \times 20 \times 20 \mathrm{~cm}^{3}\right)$ used as substrate.

The concrete blocks have been provided by Rocholl GMBH company and they comply with the European Standard EN 1766:2000 on concrete substrates designed for repair materials testing. Since the roughness of the substrate is a major parameter involved in adherence and cracking (Garbacz et al., 2008), its control is crucial to obtain reproducible test. The surfaces of the blocks were sandblasted with a blasting depth of 1-2 $\mathrm{mm}$. Concrete blocks were kept for at least two weeks in the testing room.

\section{DIC principles.}

The digital image correlation method is based on the comparison of two images with two random gray levels recorded before and after a displacement. The first picture is called "reference" and the second "deformed". The correlation consists in determining the degree of similarity (in terms of conservation of optical flux) between these two pictures. The displacement measurement consists in finding the best displacement field which allows overlying the pattern of the "reference" image and those of the "deformed" image using a pattern-matching algorithm.

In the present study, DIC is carried out using Correli-Q4-LMT, software developed in the LMT laboratory (see http://www.lmt.ens-cachan.fr/PDFs/HILD.2008.7.pdf and Besnard et al., 2006)

\section{DIC measurements}

The optical device (a CANON EOS 450D camera placed above the mortar surface) was used to monitor the evolution of the surface displacement. From the beginning of drying, images $(1157 \times 1737$ pixels $)$ of the surface were recorded every ten minutes for ten days. The time exposure was set to 1 second and the surface was lighted up by several LED lights in order to limit the optical noise.

In the restraint test, the adopted device, displayed in Figure 1, allows for following surface and in-depth displacements (and cracking). 


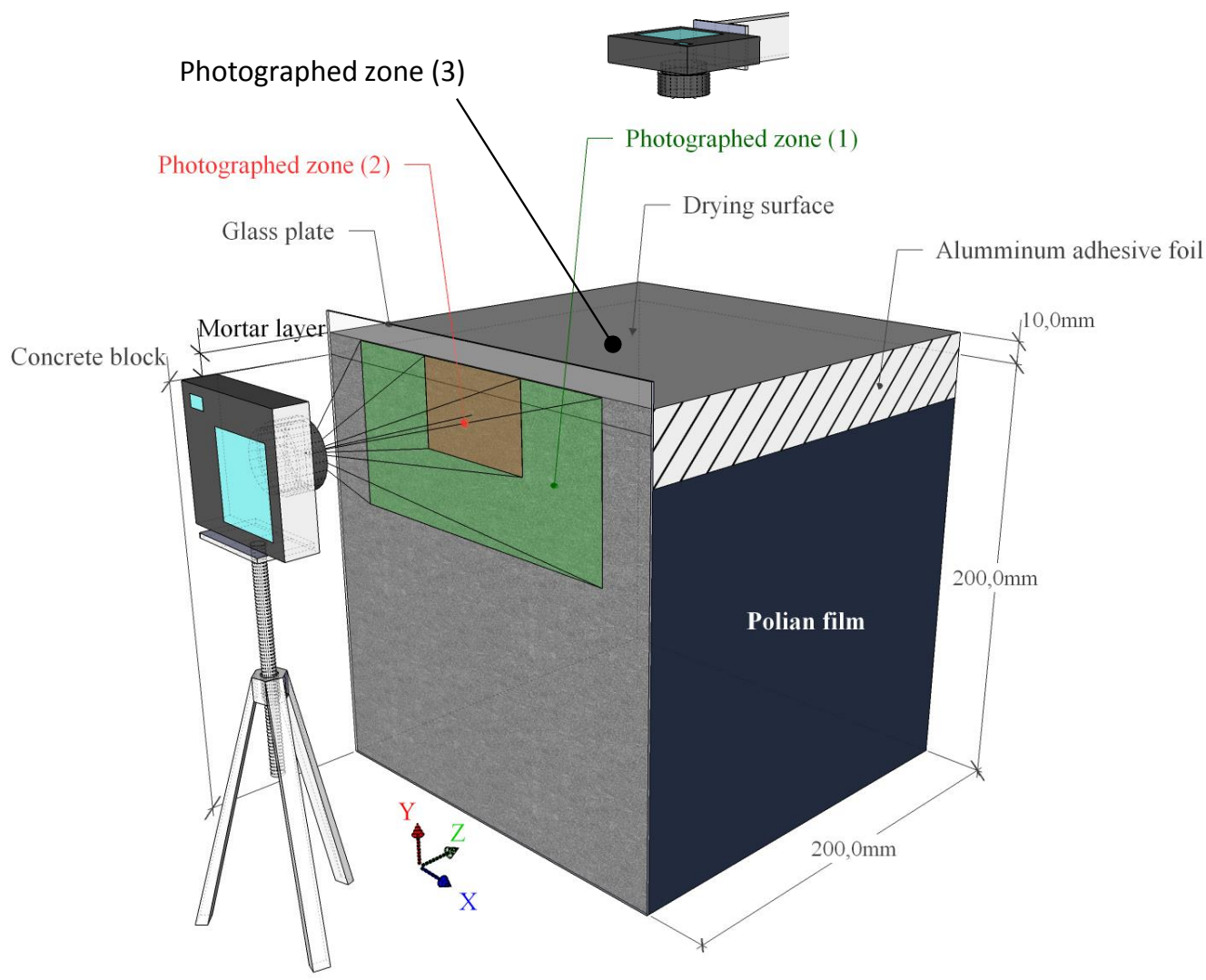

Figure 1. Experimental devices in the restrained shrinkage test: measurement of the surface and in-depth displacement.

\section{Post-processing.}

Strain tensor is calculated thanks to the small strain hypothesis (the displacement gradient is computed after interpolation of the displacement by Q4 finite elements):

$$
\boldsymbol{\varepsilon}(\mathbf{x})=\frac{1}{2}\left(\operatorname{Grad}(\mathbf{U}(\mathbf{x}))+{ }^{T} \operatorname{Grad}(\mathbf{U}(\mathbf{x}))\right) \text { with } \mathbf{U}(\mathbf{x})=\sum_{i=1}^{i=n} N_{i}(\mathbf{x}) \mathbf{U}_{i}^{e}
$$

where $\boldsymbol{\varepsilon}$ is the strain tensor (2D) and $\mathbf{U}$ is the displacement vector depending upon the position vector $\mathbf{x} . N_{i}$ are Q4 (linear) scalar shape function (the same function as in finite element calculations), $n$ is the number of nodes and $\mathbf{U}^{\mathbf{e}}$ are the nodal displacements obtained by digital image correction Cracking due to restraint of shrinkage (cracking in mode I) is related to 1D tension. As conventionally done in continuum damage mechanics for cement-based materials, an equivalent tensile (positive) strain was computed as follows in order to characterize cracking with a single scalar value (Mazars, 1986):

$$
\hat{\varepsilon}=\sqrt{\langle\boldsymbol{\varepsilon}\rangle_{+}:\langle\boldsymbol{\varepsilon}\rangle_{+}}
$$

where \langle\rangle$_{+}$is the positive part operator. From this equivalent strain, the following criterion $f$ can be derived:

$$
f=\hat{\varepsilon}-\kappa_{0}
$$


where $\kappa_{0}$ is the tensile strain threshold. This allows us to assess accurately damage/cracking in tension knowing the 2D strain tensor.

This criterion, used previously by Lagier et al. (2011) for studying drying cracks in cement pastes, is relevant for cement-based materials due to their very low tensile deformability (and low tensile strength).

\section{EXPERIMENTAL RESULTS}

\section{Validation of DIC by comparison in free shrinkage test}

It should be note that autogeneous shrinkage was found to be largely negligible for such high w/c ratio (Monge, 2007). The final displacement field (after 11 days, along the $\mathbf{x}$ direction), calculated by Corelli_Q4_LMT, is given in Figure 2(a). Almost uniform gradients of displacement field along the $\mathbf{x}$ axis and (the $\mathbf{y}$ axis, not represented) can be observed (by plotting displacements $U_{x} / U_{y}$ versus $x / y$ coordinates, respectively). It should be noticed that, in each direction, iso-values of displacement were slightly incurved on the sides of the plate. This phenomenon may be due to a slight drying of the lateral sides (induced by the peeling of aluminum adhesive foils) or by slight curling (induced by the presence of wood sticks which modify partially drying). DIC measurements depend strongly on the frame surface quality (Hild et al., 2002). In order to validate the proposed procedure, the displacement measured by DIC was used to determine the "mean" strain in the mortar specimen. The comparison with measurements with a classical LVDT is plotted in Figure 2(b). The rather good agreement between the two measurement methods indicates that the DIC method is efficient for obtaining displacement and strain fields during drying for several days.

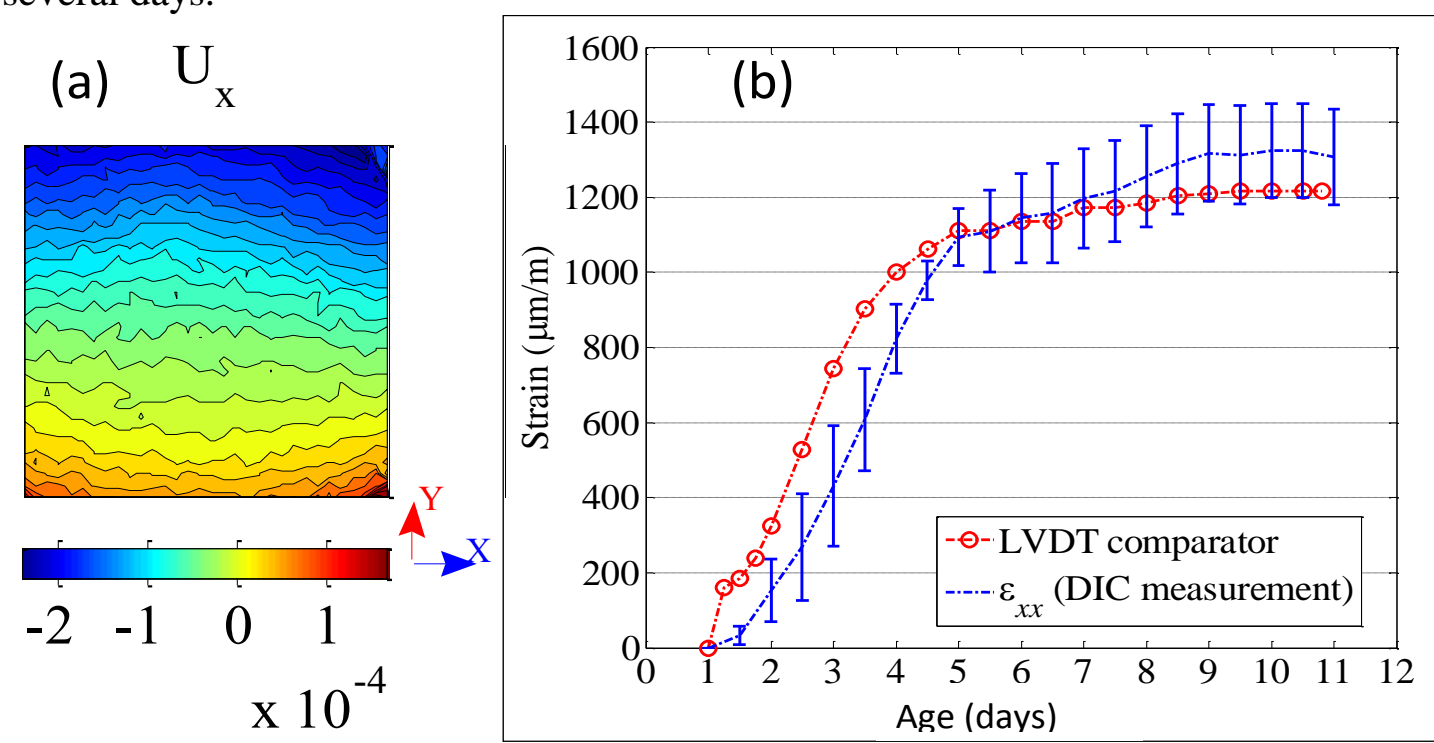

Figure 2. Free drying shrinkage strains obtained by DIC and LVDT

\section{Surface cracking in restraint tests}


At the end of the restrained shrinkage test, no macro-crack (i.e. visible to naked eye) was observed. Only micro-cracks (i.e. only visible with optical microscope) on the whole surface were detected. These qualitative observations have been retrieved quantitatively by DIC. The post-processing tool displays the field of the criterion (see Eq. 2 and 3, only positive values are displayed), which reveals the apparition of a micro-cracking network at the surface (Figure 3 ). The pattern of cracks (3 joining cracks) is typical of cracking due to the restraint of drying shrinkage. After cracking initiation, the global shape of the cracks network remained the same throughout the test. However, the intensity of the equivalent tensile strain (Eq. 2) increased during the test, corresponding to an increase of the crack widths. The method does not allow us to determine accurately the time of cracking initiation. Indeed, at this time, the tensile strains are of the same order of magnitude than the resolution of the measure.
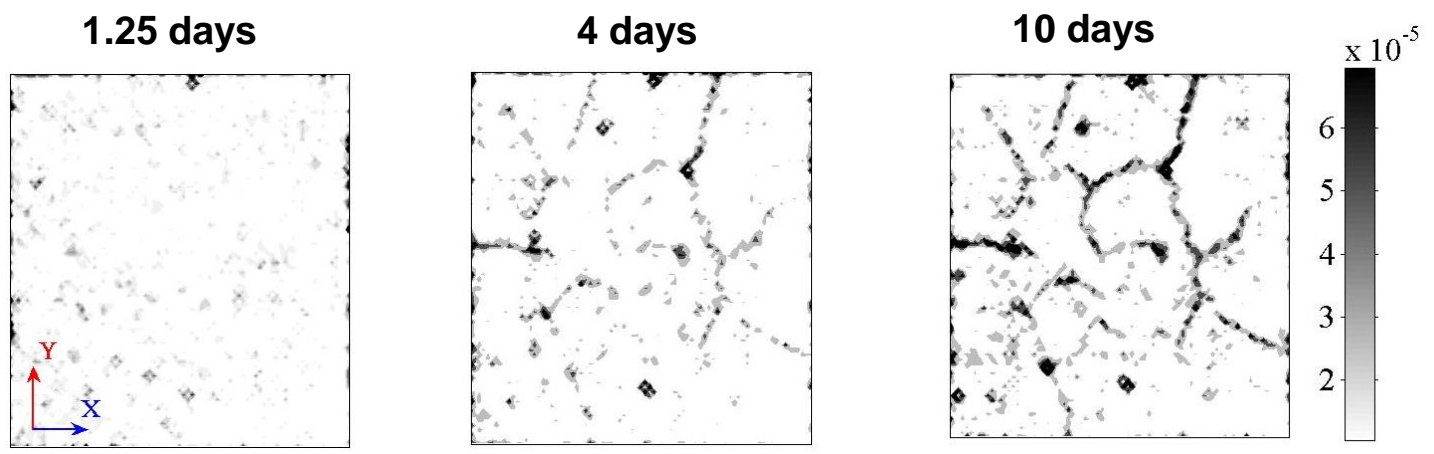

Figure 3. Micro-cracking pattern on the mortar surface $(20 \times 20 \mathrm{~cm})$ during the restrained shrinkage test (Figure 1, photographed zone 3) - Iso-values of equivalent strain of Mazars (1986) in $\mathrm{m} / \mathrm{m}$ at different ages.

\section{In-depth cracking in restraint tests}

The previous results do not give any information on the depth of cracks in the mortar and on the cracking at the interface between mortar and substrate. The observation shown below gives more insight on these aspects. However, it should be emphasized that the zone observed by camera through the glass plate is not representative of the material core (photographed zone (2) in Figure 1). In the studied area, three tensile cracks propagated through the mortar layer and reached the interface with the concrete support.

Crack widths were determined at the middle of the mortar layer (line A'-B' in the cartography of equivalent strain given in Figure 4). In order to obtain an accurate measurement, some precautions should be taken. Indeed, the image texture of the ZOI where the crack occurred is modified by the presence of the crack. The observed displacement gaps correspond to the cracks. Then, the crack width can be calculated as the difference of displacement between the interpolated displacements along the line A'-B'. This interpolation method allows us to determine crack widths, for 
instance 25.6, 16.6 and $14.6 \mu \mathrm{m}$ (Figure 4) after 10 days. These values are of the same order of magnitude than those found by optical microscopy.

The same method has been used to determine the debonding at the interface between the mortar layer and the concrete support. For instance, a displacement gap of $25 \mu \mathrm{m}$ has been found.

Three experiments were conducted on concrete blocks with controlled roughness in order to assess the reproducibility. Due to material heterogeneities and random location of defaults, the crack locations and widths observed were variable from one sample to another.
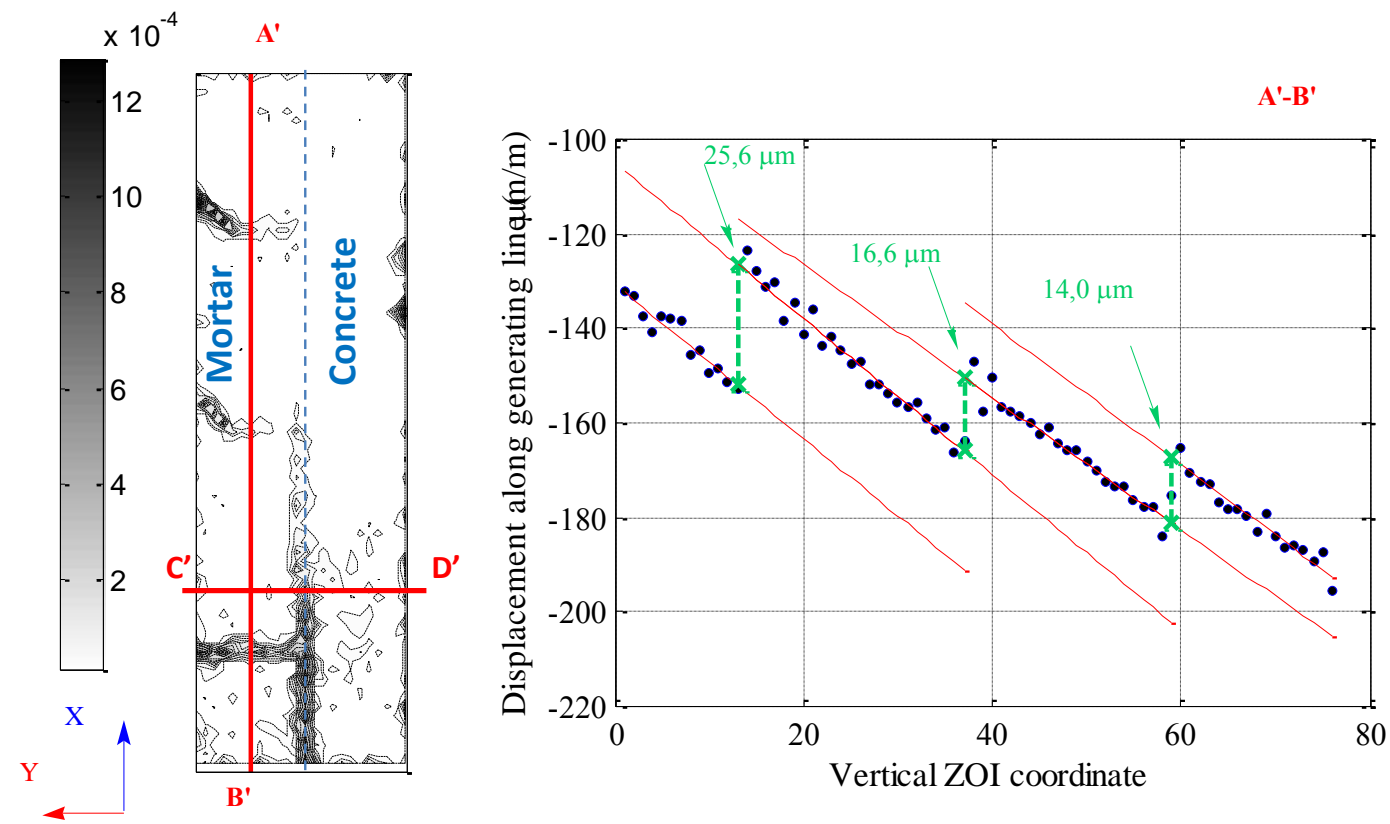

Figure 4. Micro-cracking pattern during the restrained shrinkage test (Figure 1, photographed zone 2) - Iso-values of equivalent strain of Mazars (1986) in $\mathbf{m} / \mathbf{m}$ (left hand side). Determination of crack openings by interpolation from the displacement field (right hand side) after 10 days.

\section{CONCLUSION}

The cracking evolution due to restrained drying shrinkage is hardly measurable but its monitoring is necessary to improve the understanding of mortar/substrate systems behavior. For this purpose, a new experimental method using Digital Image Correlation (DIC) was presented. Based on a post-processing of images obtained by a camera, after painting a random pattern on the studied surface, the device was developed in order to monitor 2D displacements fields. The proposed method enables also a mapping of the cracking surface and a quantification of cracks openings (indepth cracking, debonding at the interface). Based on these results, it can be 
concluded that DIC method is a promising tool to study coating mortar cracking with representative geometries and in restraint conditions.

Besides, almost all relevant material parameters (related to the evolutions of hydration degree, Young modulus, tensile strength, drying, drying shrinkage ...) have been measured. The next objective is then to perform numerical simulations in order to validate a model which is currently under improvement. In contrary to previous studies, it is possible using DIC to compare experimental with predicted displacements, not at predefined locations (corresponding to sensors), but in the whole surface. Furthermore, since cracks initiate at random areas, depending on local defaults, it is difficult to discriminate models. Using DIC, it is possible to extract the boundary conditions in term of displacements and to impose them for finite element calculations.

\section{REFERENCES}

Besnard, G., Hild, F., and Roux, S. (2006). "Finite-element" displacement fields analysis from digital images: Application to Portevin-Le Châtelier bands." Exp. Mech., 46, 789-804.

Garbacz, A., Courard, L., and Kostana, K. (2006). "Characterization of concrete surface roughness and its relation to adhesion in repair sytems." Mater. Charact., 56, 281-289.

Lagier, F., Jourdain, X., De Sa, C., Benboudjema, F., Colliat, J.-B. (2011). "Numerical strategies for prediction of drying cracks in heterogeneous materials: comparison upon experimental results." Engineering Structures, 33(3), 920 931

Mazars, J., "A description of micro and macroscale damage of concrete structures." Eng. Fract. Mech., 25, 729-737.

Monge, J. (2007). Fissuration des mortiers en couches minces - Effets de l'hydratation, du séchage et de la carbonatation, $\mathrm{PhD}$ Thesis, ENS Cachan, in french.

Hild, F., Raka, B., Baudequin, M., Roux, S., Cantelaube, F. (2002). "Multi-scale displacement field measurements of compressed mineral wool samples by digital image correlation." Appl. Opt., 32, 6815-6828. 